\title{
Erratum to: Review of post-collisional volcanism in the Central Anatolian Volcanic Province (Turkey), with special reference to the Tepekoy Volcanic Complex
}

\author{
Gonca Gencalioglu Kuscu • Fatma Geneli
}

Published online: 24 December 2009

(C) Springer-Verlag 2009

\section{Erratum to: Int J Earth Sci (Geol Rundsch)} DOI 10.1007/s00531-008-0402-4

Unfortunately, the fields E-MORB and N-MORB in Fig. 10d are mislabeled. The correct figure version is:
The online version of the original article can be found under doi:10.1007/s00531-008-0402-4.

G. Gencalioglu Kuscu ( $\square)$

Department of Geological Engineering,

Mugla University, 48000 Mugla, Turkey

e-mail: gkuscu@mu.edu.tr; gkuscu@eos.ubc.ca

\section{F. Geneli}

Department of Geological Engineering,

Middle East Technical University,

06532 Ankara, Turkey

e-mail: fgeneli@metu.edu.tr
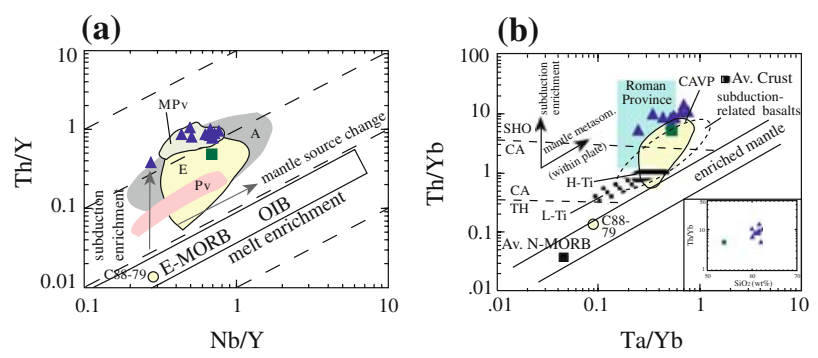

(c)
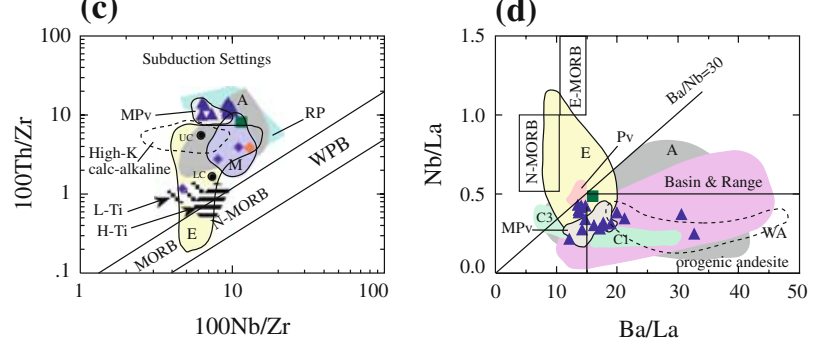

(e)
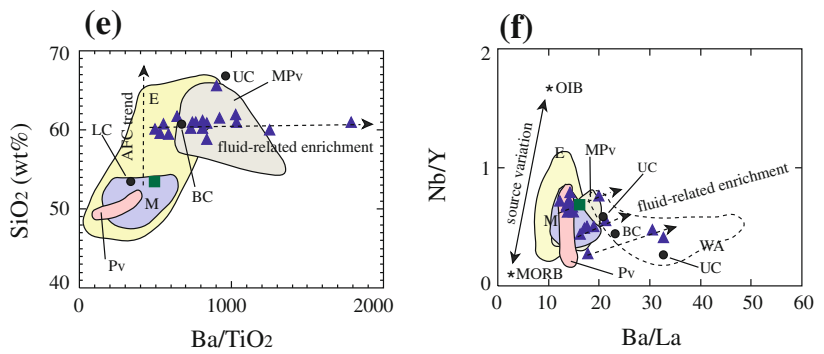

Accordingly, the sentence in "Source characteristics" section

"Tepekoy basaltic andesite is again closely associated with the Pv samples in this diagram, and plots close to E-MORB" should read

"Tepekoy basaltic andesite is again closely associated with the Pv samples in this diagram, and plots close to N-MORB". 